\title{
Studies of ovulation in the perfused ovary of the fowl (Gallus domesticus)
}

\author{
K. Tanaka, Z. D. Li and Y. Ataka \\ Faculty of Agriculture, Kyushu University, Fukuoka 812, Japan
}

\begin{abstract}
Summary. A system was developed for the in-vitro perfusion of the fowl ovary. The ovaries were isolated $16-18 \mathrm{~h}$ before expected ovulation of the first follicle of a clutch sequence and perfused at $41^{\circ} \mathrm{C}$ with Eagle's culture medium containing L-thyroxine and insulin. The efferent perfusion pressure was maintained at $30-40 \mathrm{mmHg}$. This model was used to investigate the mechanism of ovulation.

Addition of $\mathrm{LH}(1 \mathrm{U})$ to the perfusate induced ovulation $(46 \%)$ but $\mathrm{LH}$ $(1 \mathrm{U})+$ FSH $(1 \mathrm{U})$ was more effective $(88 \% ; P<0.05)$. Progesterone at $100 \mu \mathrm{g}$ alone also induced ovulation $(80 \%)$. Clomiphene prevented gonadotrophin-induced ovulation. These results suggest that progesterone may act directly on the ovary as a final hormone to induce ovulation in the domestic fowl.
\end{abstract}

\section{Introduction}

There have been many studies of the endocrine control of ovulation in the domestic fowl. Fraps \& Dury (1943) were the first to induce premature ovulation in laying hens by an injection of progesterone. Later, Fraps (1961) suggested that preovulatory secretion or release of luteinizing hormone ( $\mathrm{HH}$ ) is controlled by the hypothalamus which is responsive to the "excitatory' hormone, possibly progesterone, secreted by the preovulatory follicle. At present it is well documented that the preovulatory surge of $\mathrm{LH}$ in the hen is associated with increased plasma concentrations of steroid hormones (Furr et al., 1973; Senior \& Cunningham, 1974; Laguë et al., 1975; Shodono et al., 1975; Etches \& Cunningham, 1977; Williams \& Sharp, 1978) and that exogenous LH stimulates the granulosa cells to enhance the production of progesterone (Culbert et al., 1980; Wells et al., 1980; Hammond et al., 1981). Furr \& Smith (1975) found that the administration of antisera to progesterone or testosterone, but not to oestradiol, can block ovulation. Similar results using steroid blockers have been reported by Tojo \& Huston (1981), Johnson \& van Tienhoven (1984) and Lang et al. (1984a, b). Exogenous progesterone and testosterone are also effective in the release of LH (Wilson \& Sharp, 1975, 1976b; Etches \& Cunningham, 1976). Extensive studies on the role of these steroids revealed that testosterone may not participate in the preovulatory secretion of $\mathrm{LH}$, indicating that progesterone is the most likely steroid hormone involved in ovulation in hens (Wilson \& Sharp, 1976c; Luck, 1982). Tanaka et al. (1985) suggest that progesterone could be a final hormone which plays a direct role in follicular rupture and extrusion of the hen's ovum. However, the mechanisms causing rupture of the follicle in the domestic fowl have not been completely elucidated, since explanations of observations obtained from in-vivo experiments are complicated by uncontrollable variables, including endocrine, neural, humoral, vascular and metabolic factors.

The present investigation was undertaken (1) to design an apparatus and technique for in-vitro perfusion of the fowl ovary, and (2) to clarify the role of gonadotrophins and progesterone in relation to ovulation. 


\section{Materials and Methods}

\section{Experimental procedure}

Birds from a commercial hybrid egg-laying stock were used. They were maintained in individual laying cages fitted with automatic oviposition recorders and were exposed to a 14 -h photoperiod. All hens selected for study were producing clutches of more than 3 eggs with a pause of only a single day between clutches.

Hens were injected intravenously with heparin sulphate ( $100 \mathrm{U} / \mathrm{hen}) 16-18 \mathrm{~h}$ before expected ovulation of the first follicle of a clutch sequence and killed by cutting the jugular vein. Working rapidly, the breast was removed and the viscera were displaced to one side, permitting a good view of the ovary, followed by pouring cold Eagle-citrate medium (Medium EC) on the ovary to avoid 'warm ischaemia' as defined by Ahrén et al. (1972). While continuing to cool the ovary in this manner, a cannula was inserted and securely tied into the dorsal aorta just anterior to the coeliac artery (see Nalbandov \& James, 1949). The branch arteries and the tip of the cannula together with the dorsal aorta were ligated as shown in Fig. 1. The cannula, made of Silastic tubing (Dow Corning, Midland, MI, U.S.A.), is $2 \mathrm{~mm}$ in outer diameter and $40 \mathrm{~mm}$ long with two pairs (bilateral) of small holes from which perfusate runs out and enters the ovary through the ovarian artery (Fig. 1).

During the operation the ovary was continuously flushed by a roller pump with cold Medium EC to wash out the remaining blood and fat in the ovarian vessels. This pre-perfusion system consisted of 2 major portions: a reservoir of Medium EC $(100 \mathrm{ml})$ and a roller pump. Medium EC consisted of equal volumes of Eagle's culture medium (Nissui Pharmacol. Co., Toyoshima-ku, Tokyo, Japan) and $0.25 \mathrm{M}$-trisodium citrate.

The cannulated ovary was dissected free, disconnected from the efferent tube of the pre-perfusion system, and connected with the recycling perfusion apparatus. The ovary was then placed in an ovarian perfusion chamber, followed by immersion in a water bath maintained at $41^{\circ} \mathrm{C}$ (Fig. 2). In general, warm ischaemia lasted a maximum of $6 \mathrm{~min}$ before cannulation. The operative technique used was a simplified form of the technique of aseptic human surgery.

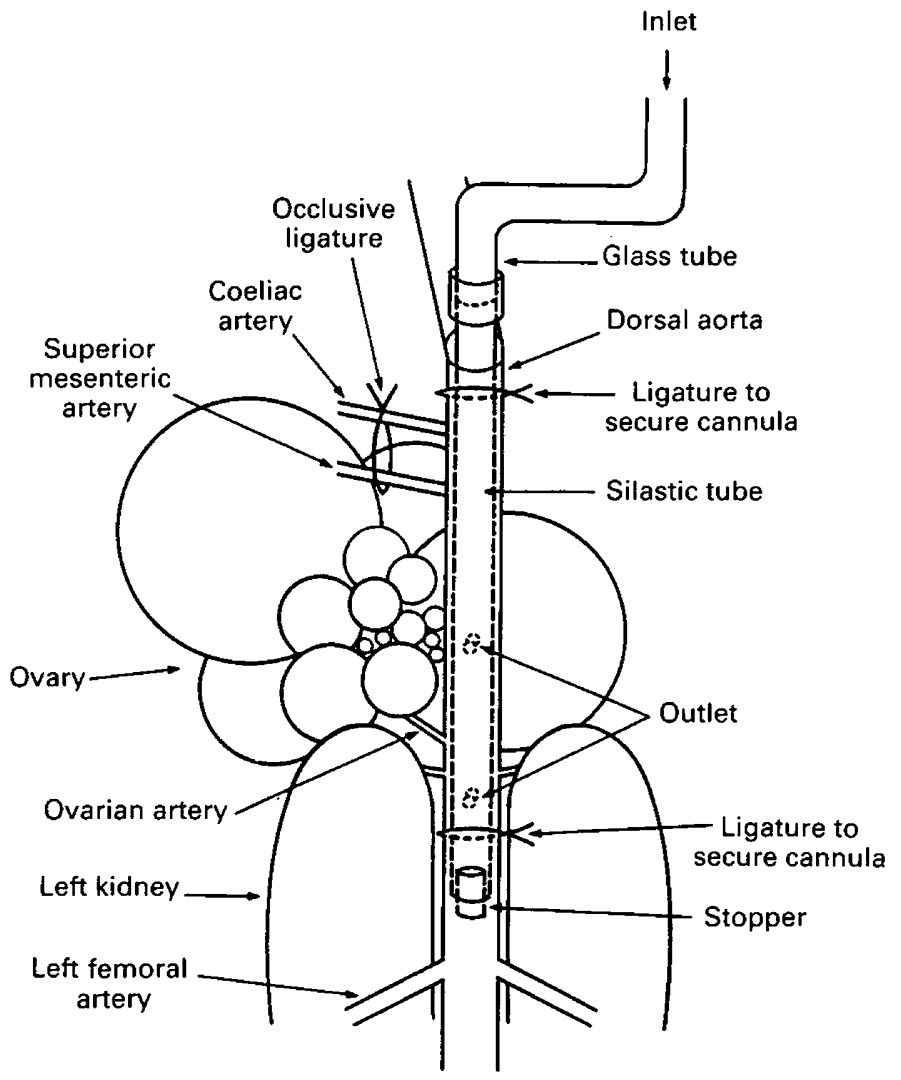

Fig. 1. Schematic drawing of cannulation for perfusion of the fowl ovary. 


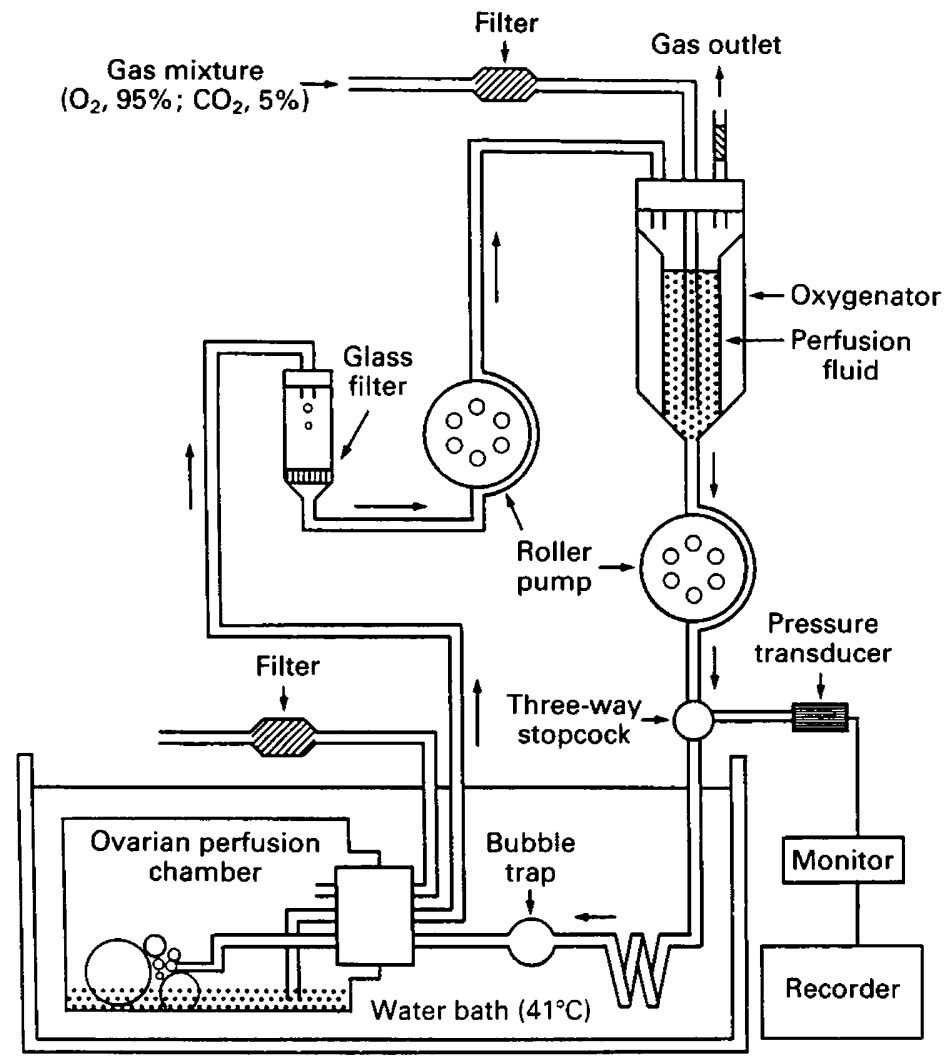

Fig. 2. Schematic representation of the perfusion apparatus.

Recycling perfusion system. The perfusion apparatus consisted of 6 major portions: an ovarian perfusion chamber, a glass filter, two roller pumps, an oxygenator (bubble type), and a pressure transducer (Fig. 2). The perfusion fluid, a total of $500 \mathrm{ml}$, was oxygenated with a gas mixture of $95 \% \mathrm{O}_{2}$ and $5 \% \mathrm{CO}_{2}$ in the oxygenator $(\sim 600 \mathrm{ml}$ volume). The gas flow rate during these experiments was about $10 \mathrm{ml} / \mathrm{min}$. Oxygenated perfusate was drawn from the oxygenator through a flexible Silastic tube ( $5 \mathrm{~mm}$ o.d.) and a bubble trap, and transferred to the ovary by a roller pump. The cannula was passed through a Silastic stopper to seal the perfusion chamber which was immersed in a water bath. The perfusate flowing from unligated ovarian veins was pumped up from the perfusion chamber reservoir, transferred to the oxygenator through a glass filter, and re-circulated (Fig. 2). The efferent perfusion pressure was maintained at $30-40 \mathrm{mmHg}$ and flow rate of perfusate was $2.0-7.5 \mathrm{ml} / \mathrm{min}$. All perfusions were operated for $3-10 \mathrm{~h}$ in sterile conditions. When rupture or atresia of the largest follicle took place during perfusion, perfusion was discontinued.

The perfusion fluid ( $\mathrm{pH} 7 \cdot 4,1$ litre) consisted of Eagle's culture medium containing $100 \mu \mathrm{g}$ L-thyroxine dissolved in $0 \cdot 2 \mathrm{ml} 0 \cdot 1 \mathrm{M}-\mathrm{NaOH}+0 \cdot 15 \mathrm{M}-\mathrm{NaCl}(1: 9 \mathrm{v} / \mathrm{v}), 20 \mathrm{U}$ insulin (Isuzulin-40, Takeda, Chem. Co., Higashi-ku, Osaka, Japan) and 1 g glucose.

Preparations of hormones and steroid blocker. Progesterone (20 mg, Sigma, Chem. Co., St Louis, MO, U.S.A.) was dissolved in absolute ethanol $(1 \mathrm{ml})$, followed by mixing with ethylene glycol $(39 \mathrm{ml})$. Three concentrations of progesterone, 50,100 and $200 \mu \mathrm{g} / \mathrm{litre}$, were studied by adding $0 \cdot 1,0 \cdot 2$ and $0.4 \mathrm{ml}$ of the hormone preparation respectively to 1 litre of perfusion fluid. In routine work 2 separate perfusion systems containing $500 \mathrm{ml}$ perfusion fluid/ovary/system were operated simultaneously. Ovine LH (NIAMDD-oLH-22, 2.3 U/mg) and FSH (NIAMDD-oFSH-13, 15 U/mg) were generously provided by the National Pituitary Agency. Each of these hormones were dissolved in $0 \cdot 15 \mathrm{M}-\mathrm{NaCl}$ to make $1 \mathrm{U} / \mathrm{ml}$. Two doses of $\mathrm{LH}, 0.2$ and $1.0 \mathrm{U}$ which are equivalent to 86 and $430 \mu \mathrm{g}$ respectively, were tested by adding 0.2 or $1.0 \mathrm{ml}$ of the LH preparation to 1 litre of perfusion fluid. When LH (1 U) in combination with FSH ( $1 \mathrm{U}$ ) was studied, $1 \mathrm{ml}$ of the $\mathrm{LH}$ and $1 \mathrm{ml}$ of the FSH preparations were added to 1 litre of perfusion fluid. Clomiphene citrate (Sigma) was dissolved in ethylene glycol to make $30 \mathrm{mg}\left(5 \times 10^{-5} \mathrm{~mol}\right) / \mathrm{ml}$ and $1 \mathrm{ml}$ of this preparation was added to 1 litre of perfusion fluid. This is equivalent to $5 \times 10^{-5} \mathrm{M}$.

The hormones or steroid blocker to be tested were added to the perfusion fluid at the onset of perfusion. Significance levels for the percentage of the largest follicles ovulating were determined by $\chi^{2}$ tests. 


\section{Results}

The ovulation responses of the perfused ovaries are shown in Table 1. There was no ovulation in control ovaries, $<50 \%$ ovulation with $\mathrm{LH}$ alone and the lowest and highest doses of progesterone but $>80 \%$ ovulation with the other treatments.

In general, the interval between the onset of perfusion and ovulation was about $4 \mathrm{~h}$. The follicles which failed to ovulate always became atretic by $8 \mathrm{~h}$ after the start of perfusion. Once initiated, atresia rapidly spread to the entire surface of the follicle, usually within $1 \mathrm{~h}$.

Clomiphene prevented gonadotrophin-induced ovulation (Table 1).

Table 1. Effects of hormones on the induction of ovulation in the perfused ovary

\begin{tabular}{|c|c|c|c|}
\hline \multirow{2}{*}{$\begin{array}{l}\text { Hormone } \\
\text { (per litre) }\end{array}$} & \multirow{2}{*}{$\begin{array}{l}\text { No. of } \\
\text { ovaries } \\
\text { perfused }\end{array}$} & \multicolumn{2}{|c|}{$\begin{array}{l}\text { No. of } \\
\text { follicles }\end{array}$} \\
\hline & & Ruptured & $\%$ \\
\hline $\mathrm{LH}(0.2 \mathrm{U})$ & 7 & $3(1)$ & $43^{b}$ \\
\hline LH (1 U) & 13 & $6(3)$ & $46^{\mathrm{b}}$ \\
\hline $\mathrm{LH}(1 \mathrm{U})+\mathrm{FSH}(1 \mathrm{U})$ & 8 & $7(3)$ & $88^{\mathrm{c}}$ \\
\hline FSH (1 U) & & & \\
\hline $\begin{array}{l}+ \text { progesterone }(100 \mu \mathrm{g}) \\
\text { Progesterone }\end{array}$ & 13 & $11(5)$ & $85^{\circ}$ \\
\hline $50 \mu \mathrm{g}$ & 10 & $4(0)$ & $40^{\text {bd }}$ \\
\hline $100 \mu \mathrm{g}$ & 10 & $8(2)$ & $80^{\mathrm{cd}}$ \\
\hline $200 \mu \mathrm{g}$ & 11 & $1(0)$ & $9^{a}$ \\
\hline $\begin{array}{l}\mathrm{LH}(\mathrm{I} \mathrm{U})+\mathrm{FSH}(1 \mathrm{U}) \\
\quad+\text { clomiphene }\left(5 \times 10^{-5} \mathrm{M}\right) \\
\mathrm{LH}(1 \mathrm{U})+\mathrm{FSH}(1 \mathrm{U})\end{array}$ & 8 & $1(0)$ & $13^{\mathrm{a}}$ \\
\hline + ethylene glycol ( $1 \mathrm{ml})$ & 10 & $9(2)$ & $90^{\mathrm{c}}$ \\
\hline Control & 10 & 0 & $0^{\mathrm{a}}$ \\
\hline
\end{tabular}

Values in parentheses indicate the number of complete ovulations.

Values with different superscripts are significantly different, $P<0.05$.

\section{Discussion}

The present results show that the fowl ovary can be perfused in vitro in a functional state for extended periods of time. However, prolonged periods of ischaemia, excessive handling of the follicles during isolation of the ovary, and operating the system at a lower or higher efferent perfusion pressure than a range of $30-40 \mathrm{mmHg}$ are particularly harmful for the maintenance of a functional ovary.

The fact that addition of LH in combination with FSH to the perfusate was highly effective for the induction of ovulation as compared to LH alone suggested that FSH augments the action of LH to induce ovulation. This agrees with the results of an in-vivo study by Kamiyoshi \& Tanaka (1972). The induction of ovulation by 50 or $100 \mu \mathrm{g}$ progesterone was not unexpected, since progesterone has been reported to be an important steroid in the process of follicular rupture in the hen (Furr \& Smith, 1975; Tojo \& Huston, 1981) and in hypophysectomized rats ovulation has been induced by injection of progesterone (Takahashi et al., 1974). However, the failure of ovulation at a dose of $200 \mu \mathrm{g}$ progesterone may be due to an overdose effect as reported by Wilson \& Sharp (1976a), although the detailed mechanism of this harmful effect on ovulation is unknown.

Clomiphene prevented gonadotrophin-induced ovulation. Clomiphene is reported to inhibit steroidogenesis at a step before pregnenolone (Sgarlata et al., 1984). The present results therefore 
suggest that steroid hormones are essential in the process of ovulation. In this connection, oestrogen and testosterone may be excluded from direct participation in follicular rupture (Furr \& Smith, 1975; Wilson \& Sharp, 1976c; Luck, 1982). A preovulatory surge of plasma progesterone has been reported to occur in coincidence with the highest concentration of progesterone in the largest follicle (Shahabi et al., 1975). This elevated progesterone, possibly brought about by a positive feedback action of LH, may act directly on the follicle to cause ovulation, since the present experiments have shown that ovulation can be induced in vitro by the administration of progesterone. Further work, however, is required to determine the importance of progesterone in ovulation at the follicular level in the laying hen.

We thank NIAMDD, Baltimore, Maryland, for the generous gift of the ovine LH and FSH used in these experiments. This study was supported by a Grant-in-Aid from the ministry of Education, Science and Culture (61560309).

\section{References}

Ahrén, K., Janson, P.O. \& Selstam, G. (1972) Perfusion of ovaries in vitro and in vivo. Acta endocr., Copenh., Suppl. 158, 285-209.

Culbert, J., Hardie, M.A., Wells, J.W. \& Gilbert, A.B. (1980) Effect of ovine LH on the progesterone content of the granulosa cells in preovulatory follicles of the domestic fowl (Gallus domesticus). J. Reprod. Fert. 58, 449-453.

Etches, R.J. \& Cunningham, F.J. (1976) The interrelationship between progesterone and luteinizing hormone during the ovulation cycle of the hen (Gallus domesticus). J. Endocr. 71, 51-58.

Etches, R.J. \& Cunningham, F.J. (1977) The plasma concentrations of testosterone and LH during the ovulation cycle of the hen (Gallus domesticus). Acta endocr., Copenh. 84, 357-366.

Fraps, R.M. (1961) Ovulation in the domestic fowl. In Control of Ovulation, Vol. 1, pp. 133-162. Ed. C. A. Villee. Pergamon, New York.

Fraps, R.M. \& Dury, A. (1943) Occurrence of premature ovulation in the domestic fowl following administration of progesterone. Proc. Soc. exp. Biol. Med. 52, 364-349.

Furr, B.J.A. \& Smith, G.K. (1975) Effects of antisera against gonadal steroids on ovulation in the hen Gallus domesticus. J. Endocr. 66, 303-304.

Furr, B.J.A., Bonney, R.C., England, R.J. \& Cummingham, F.J. (1973) Luteinizing hormone and progesterone in peripheral blood during the ovulatory cycle of the hen, Gallus domesticus. J. Endocr. 57, 159-169.

Hammond, R.W., Burke, W.H. \& Hertelendy, F. (1981) Influence of follicular maturation on progesterone release in chicken granulosa cells in response to turkey and ovine gonadotrophins. Biol. Reprod. 24, 1048-1055.

Johnson, A.L. \& van Tienhoven, A. (1984) Effects of aminoglutethimide on luteinizing hormone and steroid secretion, and ovulation in the hen, Gallus domesticus. Endocrinology 114, 2276-2283.

Kamiyoshi, M. \& Tanaka, K. (1972) Augmentative effect of FSH on LH-induced ovulation in the hen. $J$. Reprod. Fert. 29, 141-143.
Laguë, P.C., van Tienhoven, A. \& Cunningham, F.J. (1975) Concentrations of estrogens, progesterone and LH during the ovulatory cycle of the laying chicken (Gallus domesticus). Biol. Reprod. 12, 590-598.

Lang, G.F., Etches, R.J. \& Walton, J.S. (1984a) Effects of luteinizing hormone, progesterone, testosterone, estradiol and corticosterone on ovulation and luteinizing hormone release in hens treated with aminoglutethimide. Biol. Reprod. 30, 278-288.

Lang, G.F., Walton, J.S. \& Etches, R.J. (1984b) The effect of aminoglutethimide on steroid secretion, ovulation, and luteinizing hormone release in the hen. Poultry Sci. 63, 1861-1871.

Luck, M.R. (1982) Effects of an anti-androgen in the laying hen (Gallus domesticus). J. Reprod. Fert. 64, 381-385.

Nalbandov, A.V. \& James, M.F. (1949) The bloodvascular system of the chicken ovary. Am. J. Anat. 85, 347-377.

Senior, B.E. \& Cunningham, F.J. (1974) Oestradiol and luteinizing hormone during the ovulatory cycle of the hen. J. Endocr. 60, 201-202.

Sgarlata, C.S., Mikhall, G. \& Hertelendy, F. (1984) Clomiphene and tamoxifen inhibit progesterone synthesis in granulosa cells: comparison with estradiol. Endocrinology 114, 2032-2038.

Shahabi, N.A., Norton, H.W. \& Nalbandov, A.V. (1975) Steroid levels in follicle and plasma of hens during the ovulatory cycle. Endocrinology 96, 962-968.

Shodono, M., Nakamura, T., Tanabe, Y.\& Wakabayashi, K. (1975) Simultaneous determination of oestradiol$17 \beta$, progesterone and luteinizing hormone in the plasma during the ovulatory cycle of the hen. Acta endocr., Copenh. 78, 565-573.

Takahashi, M., Ford, J.J., Yoshinaga, K. \& Greep, R.O. (1974) Induction of ovulation in hypophysectomized rats by progesterone. Endocrinology 95, 1322-1326.

Tanaka, K., Koga, O. \& Utsumi, H. (1985) In vitro investigations of ovulation in the perfused fowl ovary. Proc. 3rd AAAP Anim. Sci. Cong., Seoul, Vol. $1,444-446$.

Tojo, H. \& Huston, T.M. (1981) Effects of steroid 
blockers on $\mathrm{LH}$-induced ovulation in the domestic fowl, Gallus domesticus. J. Reprod. Fert. 61, 381-386.

Wells, J.W., Gilbert, A.B. \& Culbert, J. (1980) Effect of luteinizing hormone on progesterone secretion in vitro by the granulosa cells of the domestic fowl (Gallus domesticus). J. Endocr. 84, 249-254.

Williams, J.B. \& Sharp, P.J. (1978) Control of the preovulatory surge of luteinizing hormone in the hen (Gallus domesticus): role of progesterone and androgens. J. Endocr. 77, 57-65.

Wilson, S.C. \& Sharp, P.J. (1975) Changes in plasma concentrations of luteinizing hormone after injection of progesterone at various times during the ovulatory cycle of the domestic hen (Gallus domesticus). $J$. Endocr. 67, 59-70.
Wilson, S.C. \& Sharp, P.J. (1976a) The effects of progesterone on oviposition and ovulation in the domestic fowl (Gallus domesticus). Br. Poult. Sci. 17, 163-173.

Wilson, S.C. \& Sharp, P.J. (1976b) Effects of androgens, oestrogens and deoxycorticosterone acetate on plasma concentrations of luteinizing hormone in laying hens. J. Endocr. 69, 93-102.

Wilson, S.C. \& Sharp, P.J. (1976c) Induction of luteinizing hormone release by gonadal steroids in the ovariectomized domestic hen. J. Endocr. 71, 78-98.

Received 23 August 1986 